\title{
Prevalence of Controlled Systemic hypertension and its associated risk factors among hypertensive patients at Mbeya Zonal Referral Hospital, Tanzania.
}

SP Mvandal ${ }^{\circledR}$, V. Mwinuka,

\section{Correspondence to:}

Samson Peter Mvandal, Department of Health Sciences \& Public Health, PIM Foundation, Tanzania.

samsonpim@gmail.com

Keywords:

Age, adherence, antihypertensive, Controlled hypertension, clinic, hypertension, Prevalence, Systemic.

\section{ABSTRACT}

Objectives: To determine the prevalence of controlled systemic hypertension and its associated risk factors among the hypertensive patients who attended the clinic at Mbeya Zonal Referral Hospital in Tanzania.

Methods: A descriptive cross-sectional quantitative study was used determine the prevalence of co to 252 hypertensive patients were recruited during clinic visit from September to November 2020 and participant was randomly selected interviews using structured selfadministered questionnaires. Data was analyzed using chi square test to find the risk factors associated with controlled hypertension. Results: Among 252 participants, 94(39.7\%) individuals with controlled hypertension giving the prevalence of controlled hypertension. The proportion of females with controlled hypertension was slightly higher than male (49 females to 45 males). The prevalence of uncontrolled hypertension was $152(60.3 \%)$ participants. The prevalence of controlled hypertension was higher among patients who have regular clinic visit $(p<.05)$ and have daily adherence to their antihypertensive medication. A similar trend was observed among participants without financial challenges to attend clinic, short duration of illness, higher level of education and there was no association between age, sex, marital status, smoking, alcohol consumption, having health insurance and having chronic illness.

Conclusion: Prevalence of controlled hypertension is higher among patients who have regular clinic visit and have daily adherence to their anti-hypertensive medication. Also, it is higher among participants without financial challenges to attend clinic so they can have regular clinic visit and checkup. Reinforcement on regular drug intake and clinic visit, good nutrition and reduced salt intake and modifying lifestyles of patient with hypertension is important. 


\section{INTRODUCTION}

Hypertension is among the leading causes of death in Tanzania, and also it is a public health rattrap. This affecting most people in Tanzania, whereby life modification factors are less considered. It is a common non-communicable disease which may lead to cardiovascular diseases, heart failure and sometimes sexual dysfunction. ${ }^{[1]}$

In 2010, the global burden of hypertension was estimated at $\sim 1.4$ billion, and is likely estimated to exceed 1.6 billion by 2025. In 2016, non-communicable diseases accounted for 40.5 million or $71 \%$ of deaths globally; 17.9 million (44\%) of non-communicable disease related deaths were due to cardiovascular disease with hypertension as the leading risk factor. ${ }^{[2]}$

According to WHO 2013, explained controlled hypertension as average systolic blood pressure < $140 \mathrm{mmHg}$ and an average diastolic blood pressure of $<90 \mathrm{mmHg}$. All these factors based on both risk factor approach and cardiovascular approach. ${ }^{[2,3]}$

Studies done in sub-Sahara Africa (SSA) indicate that hypertension is a widespread problem, and it has been reported to be as high as $38 \%$ in some communities. It is estimated that out of the approximately 650 million people in SSA, between 10 to 20 million may have hypertension however many countries in SSA still lack detailed information on the prevalence of hypertension. ${ }^{[4]}$ Hypertension is a growing public health problem in sub-Saharan Africa. ${ }^{[4]}$

The highest prevalence of uncontrolled hypertension is reported in sub-Saharan Africa, and treatment for hypertension is unacceptably low. Uncontrolled hypertension (UHTN) in SSA is a challenge despite increasing knowledge of hypertension care and the availability of low-cost medications. ${ }^{[5]}$ A 2013 systematic review showed a very low level of treatment (18\%) and a high $(97 \%)$ prevalence of uncontrolled hypertension in SSA ${ }^{[6]}$. Morbidities, such as stroke, associated with uncontrolled hypertension are costly to treat and pose a burden to health care systems in SSA that are already weak. High uncontrolled rates of hypertension have economic and public health implications ${ }^{[6]}$.

Among patients who have detected HTN, few are taking treatment and, among those on treatment, very few are controlled ${ }^{[7]}$. Untreated or uncontrolled, hypertension is the single largest contributor to cardiovascular disease globally, causing stroke, heart failure, coronary artery disease, and kidney disease, and also is a major contributor to kidney disease ${ }^{[8]}$.

Hypertension is often called 'the silent killer' because it is a disease that shows no early symptoms, and simultaneously, is the single most significant risk factor for heart disease, The complications of hypertension are related either to sustained elevations of blood pressure, with consequent changes 
in the blood vessels and heart, or to the accompanying atherosclerosis that is accelerated by longstanding hypertension ${ }^{[0]}$.

Hypertension burden is increasing in East Africa, local studies done in 2017 have shown an extensive evidence of growing burden of hypertension in Tanzania with variation in prevalence, there is extensive evidence of the growing burden of chronic diseases in both rural and urban populations of Tanzania. ${ }^{[10]}$ Between 1990 and 2000, the prevalence of hypertension ranged from $3-27 \%$ in rural and 5-39\% in urban. Between 2000 and 2016, hypertension prevalence ranged between $13-70 \%$ in rural and $12-65 \%$ in urban ${ }^{[10]}$.

A study done in states that hypertension in sub-Saharan Africa is a widespread problem of immense economic importance because of its high prevalence in urban areas, its frequent under diagnosis, and the severity of its complications ${ }^{[11]}$. In Tanzania for example, a study done in Northern Tanzania in 2019 showed the complications such as heart failure, stroke, renal failure, ischemic heart disease, chronic kidney disease ${ }^{[12]}$.

Several factors related to poor control include ageing, obesity, lack of exercise, gender, race, access to health care, drug adherence and co-morbid conditions such as diabetes. Results from studies suggest that it may be possible to solve this public health problem. ${ }^{[13]}$ This requires interdisciplinary approaches to increase patient awareness and physician adherence to guidelines to realize the full benefits of hypertension research ${ }^{[13]}$. Controlled hypertension is key to prevent hypertension related complications such as stroke, chronic kidney disease and heart failure. ${ }^{[13]}$

In a study done involving six countries in Sub-Saharan Africa around 2018, showed that between $44 \%$ to $93 \%$ of hypertensive patients were unaware of their disease, only $18 \%$ were on medication, and a mere $7 \%$ achieved adequate blood pressure control overall ${ }^{[14]}$. Also, in study done at Mafia Island in Tanzania around year 2016, out of the 118 participants who were aware of having hypertension, 68 (57.6\%) were currently taking medication. From those taking medication, only 14 (20.6\%) had controlled hypertension. ${ }^{[15]}$ Therefore aim of this study was to determine the prevalence of controlled systemic hypertension and its associated risk factors among hypertensive patient attending clinic at Mbeya Zonal Referral Hospital, Tanzania.

\section{MATERIALS AND METHODS}

The research design was descriptive cross-sectional study.

\section{Study Area}

This study was conducted at Mbeya Zonal Referral Hospital. Mbeya Zonal Referral hospital is the largest government hospital in Southern part of Tanzania, the hospital was formally upgraded from 
the former Mbeya regional hospital back in 1984, The hospital serves approximately 8 million people in seven regions namely; Katavi, Njombe, Rukwa, Ruvuma, Iringa, Songwe and Mbeya. In the realm of providing both preventive and curative health care services in the zone. The study conducted at MZRH and data collected from September to November 2020.

\section{Study population}

The study included all hypertensive patients aged 18 years and above

\section{Inclusion Criteria}

All hypertensive patients attended at Mbeya Zonal Referral Hospital and were under antihypertensive drugs who were having illness for at least 6 months, above 18 years of age and those who were willing to participate were included.

\section{Exclusion Criteria}

All hypertensive patients not on medication, less than 18 years of age and those who refused to participate in the study.

\section{Study Design and sampling}

Study participants were drawn from patient attending at hypertensive clinic at Mbeya Zonal Referral Hospital. Patients were excluded if they refused to sign informed consent. Patients' age, sex, marital status, educational level, employment, use of anti-hypertensive medication, frequency of use of medication, regular visit of clinic, presence of co-morbid condition such as diabetes and obesity, life style risk factors like cigarette smoking and alcohol consumption, use of other drugs like steroids and anti-retroviral and duration of disease were recorded on structured questionnaires.

\section{Methods of data collections}

Data was collected from the participants by two ways by using questionnaire and by measuring two blood pressure measurements using aneroid sphygmomanometer after five minutes of rest. Selfadministered Questionnaire prepared in English and Swahili language and was used to obtain information from all hypertensive patients aged 18 years and above who attended at clinic during study time.

\section{Data analysis procedure and Statistical analysis}

The data analysis planned to include descriptive and inferential statistics; data were entered into Microsoft excel and then exported to Statistical Package for Social Sciences software (SPSS version 25.0) for further analysis and presented on the percentages and table. Regression analysis was used when making comparisons between hypertensive patients with controlled hypertension and those 
with uncontrolled HTN. The analysis of strength of relationships between categorical variables were conducted using the Chi-square test. A p-value of $<0.05$ was considered to be statistically significant.

\section{Ethical consideration}

Clearance obtained from CREC and permission to conduct this study granted by Medical officer in-charge Mbeya Zonal Referral Hospital. With reference number FA:137/264/01J/14. Individual consent was considered and confidentiality was guaranteed. No participant name filled in the form to ensure confidentiality and right to withdraw.

\section{RESULTS}

\section{Socio-demographic characteristics of study population}

This study involved 252 hypertensive patients attended at Mbeya Zonal Referral Hospital (MZRH) hypertension clinic. Their socio-demographic characteristics have been summarized in the table 1 below. Among 252 participants, 52\% (131) were female and 48\% (121) were male. About 45\% (114) participants were aged between 39-59 years followed by 60-80 years who were 30.6\% (77) participants, 40.5\% (102) participants were tribes found in Southern highland of Tanzania and 59.5\% (150) participants were non-southern highland tribes. Also 47\% (120) participants were standard seven leavers, 65.9\% (166) participants were married, 33.3\% (84) participants were peasants and the income range per month for many participants lies between 20000-100000 Tanzania shillings which was $54.8 \%$ of all participants. 
Table 1: Sociodemographic characteristics of the study population

\begin{tabular}{|c|c|c|}
\hline Variable & Frequency & Percent $(\%)$ \\
\hline \multicolumn{3}{|l|}{$\overline{\operatorname{Sex}}$} \\
\hline Male & 121 & 48.0 \\
\hline Female & 131 & 52.0 \\
\hline \multicolumn{3}{|l|}{ Age } \\
\hline $18-38$ & 48 & 19.0 \\
\hline $39-59$ & 115 & 45.6 \\
\hline $60-80$ & 77 & 30.6 \\
\hline$>80$ & 12 & 4.8 \\
\hline \multicolumn{3}{|l|}{ Education level } \\
\hline No formal education & 52 & 20.6 \\
\hline Primary education & 120 & 47.6 \\
\hline Above primary level & 80 & 31.78 \\
\hline \multicolumn{3}{|l|}{ Marital status } \\
\hline Married & 166 & 65.9 \\
\hline Non-married & 86 & 34.1 \\
\hline \multicolumn{3}{|l|}{ Occupation } \\
\hline No job & 58 & 21.4 \\
\hline Farmers & 84 & 33.3 \\
\hline Non-farmers & 110 & 45.3 \\
\hline \multicolumn{3}{|c|}{ Income/month (TShs) } \\
\hline $20000-100000$ & 138 & 54.8 \\
\hline $100000-500000$ & 73 & 29.0 \\
\hline$>500000$ & 41 & 16.3 \\
\hline
\end{tabular}

Among 252 participants, there were 94 individuals with controlled hypertension giving the prevalence of controlled hypertension of $39.7 \%$ (figure 1). The proportion of females with controlled hypertension was slightly higher than male (49 females to 45 males). The prevalence of uncontrolled hypertension was $60.3 \%$ (152participants).

The prevalence of controlled hypertension was higher among patients who have regular clinic visit and have daily adherence to their antihypertensive medication. A similar trend was observed 
among participants without financial challenges to attend clinic, short duration of illness, higher level of education. (Table 2)

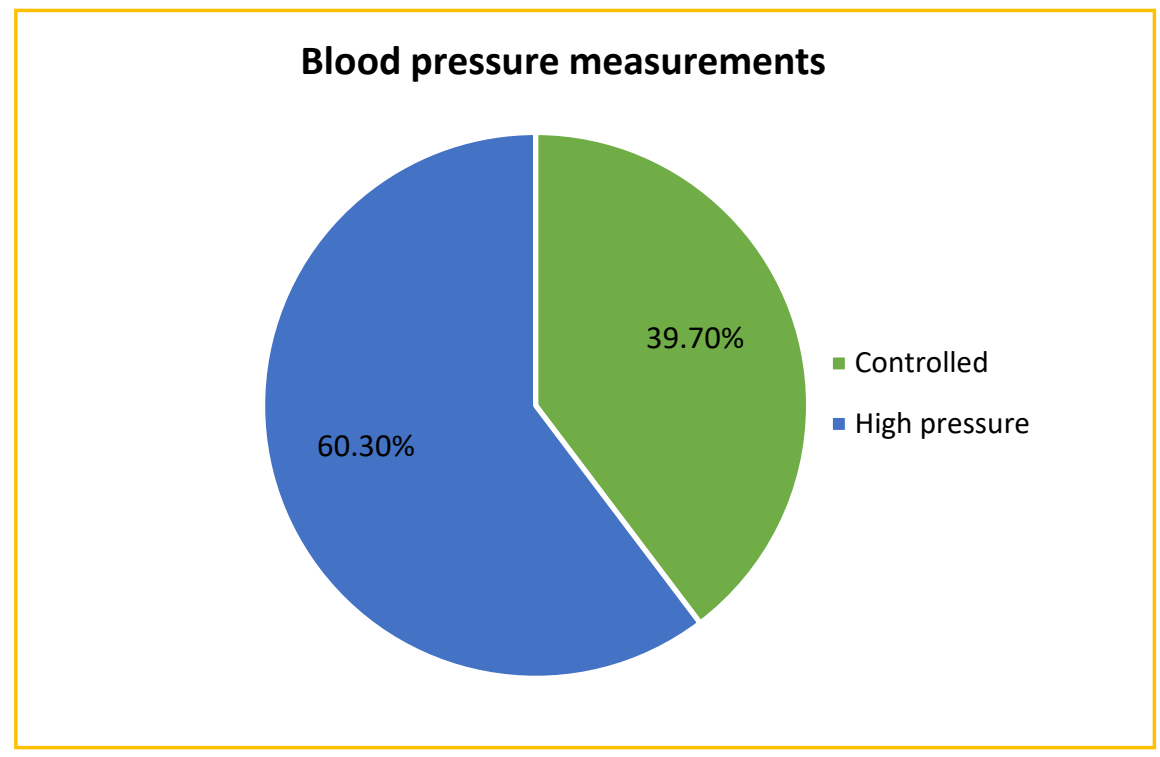

Figure 1: Prevalence of controlled hypertension

\section{Factors affecting Controlled hypertension}

The results of our study were analyzed using chi square test to find the risk factors associated with controlled hypertension. Controlled hypertension was found to have significant association with a number of variables, that included tribe $(\mathrm{p}=0.012)$, physical activities $(\mathrm{p}=0.000)$, regular clinic attendance $(p=0.000)$, adherence to antihypertensive medication $(p=0.000)$, use of table salt $(p=0.000)$, occupation $(p=0.000)$, earning per month $(p=0.018)$, education $(p=0.021)$ and duration of illness $(p=0.037)$. There was no association between age, sex, marital status, smoking, alcohol consumption, having health insurance and having chronic illness. (table 2 and table 3). 
Table 2: factors affecting controlled hypertension

\begin{tabular}{|c|c|c|c|}
\hline Variables & $\begin{array}{l}\text { Controlled } \\
\text { BP }(n=94)\end{array}$ & $\begin{array}{l}\text { Uncontrolled BP } \\
(\mathrm{n}=158)\end{array}$ & p-value \\
\hline Age & & & 0.105 \\
\hline $18-38$ & 25 & 23 & \\
\hline $39-59$ & 37 & 78 & \\
\hline $60-80$ & 33 & 44 & \\
\hline$>80$ & 5 & 7 & \\
\hline Sex & & & 0.793 \\
\hline Female & 53 & 78 & \\
\hline Male & 47 & 74 & \\
\hline Education & & & 0.021 \\
\hline No education & 18 & 34 & \\
\hline Primary & 39 & 81 & \\
\hline Secondary & 33 & 28 & \\
\hline Coll/University & 10 & 9 & \\
\hline Tribe & & & 0.012 \\
\hline Southern $\mathrm{Tz}$ aboriginal & 39 & 63 & \\
\hline Non-southern $\mathrm{Tz}$ aboriginal & 61 & 89 & \\
\hline Marital status & & & 0.592 \\
\hline Married & 61 & 105 & \\
\hline Not married & 39 & 47 & \\
\hline Occupation & & & 0.000 \\
\hline No job & 9 & 41 & \\
\hline Peasants & 32 & 52 & \\
\hline Non-peasants & 59 & 59 & \\
\hline Earning (Tsh) & & & 0.018 \\
\hline $20000-100000$ & 45 & 93 & \\
\hline $100000-500000$ & 32 & 41 & \\
\hline$>500000$ & 23 & 18 & \\
\hline
\end{tabular}


Table 3: Associated factors to controlled hypertension

\begin{tabular}{|c|c|c|c|}
\hline Variables & $\begin{array}{c}\text { Controlled BP } \\
(\mathrm{n}=94)\end{array}$ & $\begin{array}{c}\text { Uncontrolled BP } \\
(\mathrm{n}=158)\end{array}$ & p-value \\
\hline Smoking & & & 0.188 \\
\hline Yes & 10 & 24 & \\
\hline No & 90 & 128 & \\
\hline Alcohol & & & 0.596 \\
\hline Yes & 28 & 38 & \\
\hline No & 72 & 114 & \\
\hline Table salt & & & 0.000 \\
\hline Yes & 14 & 55 & \\
\hline $\mathrm{No}$ & 86 & 97 & \\
\hline Exercise & & & 0.000 \\
\hline Yes & 80 & 85 & \\
\hline $\mathrm{No}$ & 20 & 67 & \\
\hline Insurance & & & 1.000 \\
\hline Yes & 50 & 76 & \\
\hline $\mathrm{No}$ & 50 & 76 & \\
\hline Clinic attendance & & & 0.000 \\
\hline Usually & 73 & 68 & \\
\hline Often & 13 & 53 & \\
\hline Not often & 14 & 31 & \\
\hline Financial challenges & & & 0.003 \\
\hline Yes & 17 & 52 & \\
\hline No & 83 & 100 & \\
\hline Adherence & & & 0.000 \\
\hline Yes & 83 & 86 & \\
\hline No & 17 & 66 & \\
\hline Reason for not adhering & & & 0.817 \\
\hline Expensive & 9 & 34 & \\
\hline Out of stock & 3 & 12 & \\
\hline Herbal & 7 & 19 & \\
\hline Chronic illness & & & 0.237 \\
\hline Yes & 24 & 56 & \\
\hline No & 69 & 96 & \\
\hline Medication for illness & & & 0.335 \\
\hline Yes & 24 & 50 & \\
\hline No & 4 & 15 & \\
\hline Duration of HTN (years) & & & 0.037 \\
\hline$<5$ & 76 & 102 & \\
\hline $5-10$ & 20 & 49 & \\
\hline$>10$ & 4 & 1 & \\
\hline
\end{tabular}




\section{DISCUSSION}

This study was done to determine the prevalence of controlled hypertension and its associated risk factors among hypertensive patients attending at Mbeya Zonal Referral Hospital. This prevalence of controlled hypertension of $39.7 \%$ is similar to the study done at Muhimbili National Hospital of Tanzania in 2013 assessing hypertension control which showed control rate of 34\%. ${ }^{[16]}$

However the prevalence of controlled hypertension found in this study was higher than the study done in 2020 by Alfa Muhihi et al. involving seven communities of East and West Africa in subSaharan Africa which showed that among participants with prevalent hypertension, $13 \%$ had their blood pressure controlled, ${ }^{[17]}$ Also the study done in Ghana in 2018, in which the prevalence of blood pressure control was $23.8 \%$ among of patients taking anti-hypertensive medication ${ }^{[18]}$. Similarly, a study done in rural-dwelling Tanzanian older adults in 2012 reported a prevalence of controlled hypertension of $14.9 \%$ of those on regular treatment and $0.9 \%$ of all hypertensives. ${ }^{[19]}$ Also, the prevalence of controlled hypertension was lower than data from American College of Cardiology/American Heart Association (ACC/AHA) which show that the age-standardized proportion of hypertension control was $43.5 \%$ in $2015-2016 .{ }^{[1,20]}$

The difference in prevalence of controlled hypertension between various studies and this study can be explained by difference in socio-cultural aspect that affect the life style in different areas such as diet, occupation and ethnicity. ${ }^{[20]}$ Also, the time frame from which this study was done which is shorter compared to other studies. The study involved few participants (252 participants) compared to study done by American Heart Association (AHA) in 2018 which involved 38276 participants. ${ }^{[20]}$

The results of our study showed a significant association of occupation, level of education, earning per month, adherence to antihypertensive, having regular clinic attendance, reduced use of table salt, exercise, short duration of illness and controlled hypertension. ${ }^{[21]}$ This was similar to the study done in USA by Jama Network in 2020 that showed increased prevalence of hypertension control among US adults with HTN among those with versus those without a usual health care facility visit (48.4\% versus $26.5 \%$ respectively). ${ }^{[21]}$

Likewise, study done in India in 2017 showed that high education level was useful in controlling BP among hypertensive patients ${ }^{[22]}$. Moreover, similar findings were reported in study done in Southwest China in 2017, in which reduced salt intake, adherence to medication, exercise, and high economic status were responsible for controlled hypertension among those hypertensive patients on medication. ${ }^{[23]}$ 


\section{CONCLUSION}

The finding from this study show controlled hypertension is higher among patients who have regular clinic visit and have daily adherence to their antihypertensive medication. Also, it is higher among participants without financial challenges to attend clinic so they can have regular clinic visit and checkup. Other factors responsible for controlled hypertension include reduced use of table salt and physical activities which were all associated with controlled hypertension among hypertensive patients attending at Mbeya Zonal Referral Hospital.

\section{RECOMMENDATION}

Considering low rate of hypertension control among patients with hypertension, health care providers should reinforce their activities to help to improve patient's knowledge level on factors responsible for their blood pressure control such as physical activities, regular drug intake and clinic visit, good nutrition and reduced salt intake and modifying lifestyles of patients with hypertension.

\section{ACKNOWLEDGEMENTS}

The authors acknowledge with thanks, the provision of grants to conduct this research, RMO, collaborators Dr Peter Lawrence, Dioniz, Regina Mvandal. Further, we are grateful to those who were involved in the field and data collection in Mbeya, in particular Erick Msemwa. Our special thanks go to all who hypertensive patients who participated in the study.

\section{FUNDING}

This research received no external funding

\section{CONFLICTS OF INTEREST.}

The author declares no conflict of Interests exist.

\section{REFERENCES}

1. American heart association. http://www.heart.org/en/health-topics/high-bloodpressure/health-threats-from-high-blood-pressure. Assessed July 2020

2. World Health Organization, Package of Essential Non communicable (PEN) disease intervention for primary health care in low resources settings. 2013 
3. Jiapeng Lu, Yuan Lu, Harlan M.K, Lixin Jian; Prevalence and control of hypertension 2018: http://doi.org/10.1016/S0140-6736(18) 31895-5. Vol 392, issued 10155 p1306

4. Guwatudde D, Nankya-Mutyoba J, Kalyesubula R, Laurence C, Adebamowo C, Ajayi I, et al. The burden of hypertension in sub-Saharan Africa: a four-country cross sectional study. BMC public health. 2015;15(1):1-8.

5. Control CfD, Prevention. Vital signs: awareness and treatment of uncontrolled hypertension among adults--United States, 2003-2010. MMWR Morbidity and mortality weekly report. 2012; 61:703-9

6. Mohamed SF, Uthman OA, Caleyachetty R, Chumo I, Mutua MK, Asiki G, et al. Uncontrolled hypertension among patients with comorbidities in sub-Saharan Africa: protocol for a systematic review and meta-analysis. Systematic reviews. 2020;9(1):1-5.

7. Musinguzi G, Van Geertruyden JP, Bastiaens H, Nuwaha F. Uncontrolled hypertension in uganda: A comparative Cross-Sectional study. The Journal of Clinical Hypertension. 2015;17(1):63-9.

8. Fisher ND, Curfman G. Hypertensiona public health challenge of global proportions. Jama. 2018;320(17):1757-9.

9. Feng XL, Pang M, Beard J. Health system strengthening and hypertension awareness, treatment and control: data from the China Health and Retirement Longitudinal Study. Bulletin of the World Health Organization. 2013; 92:29-41.

10. Isungula K, Meda J. The Burden of Hypertension in the Rural and Urban populations of Tanzania: A review of Trends, Impacts and Response. Tanzania Journal of Health Sciences. 2017;1(1):41-52

11. Opie LH, Seedat YK. Hypertension in sub-Saharan African populations. Circulation. 2005;112(23):3562-8.

12. Hertz JT, Sakita FM, Manavalan P, Madut DB, Thielman NM, Mmbaga BT, et al. The Burden of Hypertension and Diabetes in an Emergency Department in Northern Tanzania. Ethnicity \& disease. 2019;29(4):559

13. Chiong JR. Controlling hypertension from a public health perspective. International journal of cardiology. 2008;127(2):151-6.

14. Antignac M, Diop IB, Macquart de Terline D, Kramoh KE, Balde DM, Dzudie A, et al. Socioeconomic status and hypertension control in sub-Saharan Africa: the Multination EIGHT study (Evaluation of Hypertension in Sub-Saharan Africa). Hypertension. 2018;71(4):577-84. 
15. Muhamedhussein M, Nagri Z, Manji K. Prevalence, risk factors, awareness, and treatment and control of hypertension in Mafia Island, Tanzania. International journal of hypertension. 2016;2016

16. Mwita JC, Mugusi F, Lwakatare J, Chiwanga F. Hypertension control and other cardiovascular risk factors among diabetic patients at Muhimbili National Hospital, Tanzania. East African journal of public health. 2013;10(1):337-42.

17. Okello S, Muhihi A, Mohamed SF, Ameh S, Ochimana C, Oluwasanu AO, et al. Hypertension prevalence, awareness, treatment, and control and predicted 10-year CVD risk: a cross-sectional study of seven communities in East and West Africa (SevenCEWA). BMC Public Health. 2020;20(1):1-13

18. Sanuade OA, Boatemaa S, Kushitor MK. Hypertension prevalence, awareness, treatment and control in Ghanaian population: Evidence from the Ghana demographic and health survey. PloS one. 2018;13(11):0205985.

19. Dewhurst M, Dewhurst F, Gray W, Chaote P, Orega G, Walker R. The high prevalence of hypertension in rural-dwelling Tanzanian older adults and the disparity between detection, treatment and control: a rule of sixths? Journal of human hypertension. 2013;27(6):374-80

20. Dorans KS, Mills KT, Liu Y, He J. Trends in prevalence and control of hypertension according to the 2017 American College of Cardiology/American Heart Association (ACC/AHA) guideline. Journal of the American Heart Association. 2018;7(11):e008888.

21. Muntner P, Hardy ST, Fine LJ, Jaeger BC, Wozniak G, Levitan EB, et al. Trends in blood pressure control among US adults with hypertension, 1999-2000 to 2017-2018. Jama. 2020;324(12):1190-200

22. Roy A, Praveen PA, Amarchand R, Ramakrishnan L, Gupta R, Kondal D, et al. Changes in hypertension prevalence, awareness, treatment and control rates over 20 years in National Capital Region of India: results from a repeat cross-sectional study. BMJ open. 2017;7(7): e015639.

23. Liu X, Gu W, Li Z, Lei H, Li G, Huang W. Hypertension prevalence, awareness, treatment, control, and associated factors in Southwest China: an update. Journal of hypertension. 2017;35(3):637-44. 